\title{
Madhesh Institute of Health Sciences (MIHS): A Dream Project of Medical Science in Province 2, Nepal
}

\author{
Khushbu Yadav* \\ *Department of Health Science, Mithila Technical Academy, Janakpurdham
}

\section{Dear Editor-in-chief,}

Since the promulgation of a new constitution in 2015 AD, Nepal has undergone federal restructuring into seven administrative provinces that are further sub-divided into local governance units. The turn towards federalism has created various attainable opportunities for the national healthcare system. Shifting executive power to local and provincial levels is an approach documented to have positive effects on native resource usage, through participatory bottom-up planning, enhanced responsibility and reduced bureaucracy in decision making [1]. In September 2015, the Ministry of Health and Population (MoHP) formed a high-level committee and technical working group for useful analysis of each level of the government, health system restructuring and transition management [2].

Province 2 also aimed to accelerate its health service facilities with progressive development in medical education and health science research. Despite the significant progress, equitable access to healthcare and facility towards common people remains a foremost challenge and the prospective gains are discoursed but not guaranteed in Province 2. Under Gaurav Scheme, provincial government of Province 2 established "Madhesh Institute of Health Sciences" (MIHS) on 17 $7^{\text {th }}$ Feb. 2021 at Janakpurdham based Provincial hospital as a state hold entity of province 2 , under the leadership of Honourable Chief Minister Mohammad Lalbabu Raut. MIHS officials were appointed in a function held at the office of Chief Minister and the Council of Ministers at Madhesh Bhawan [3]. It was a privilege to gaze at the inauguration ceremony of MIHS with coruscant golden letters and handing over the appointment letter of higher authorities by Chief Minister Raut to the first Vice-Chancellor, Rector and Registrar of MIHS. Province 2 government appointed Dr. Ram Kewal Sah, Professor of Orthopedic and Trauma Surgery, as the Vice-Chancellor, Dr. Ankur Sah, Professor of Radiology and member of Nepal Medical Council as Rector and Dr. Binod Kumar Yadav, Associate Professor of Biochemistry, Institute of Medicine, Tribhuvan University as Registrar of MIHS [3,4]. The appointment of qualified, competent and competitive professionals at MIHS is an exemplary to the nation with a mission to reduce suffering, disability and poverty in Province 2 by enhancing specialized health care, education and research.

The objectives of MIHS are designed to create sustainable local capacity for specialized health care of people with 500 bed specialized teaching hospital by upgrading and transformation of provincial hospital with Postgraduate education facility as early as possible. The long term plans of MIHS are to establish a facility for undergraduate teaching in medical, dental, and nursing specialty viz: MBBS, BDS, BSc/BN nursing, and several other paramedical courses along with acquisition of land, necessary equipments and construction of needful infrastructure for the development of a 700 bed teaching hospital [4].

Province 2 needs a center of excellence in medical care to provide for the health desires of its population. The formation of MIHS and also the appointment of higher dignitaries have been welcomed with a warm heart. 


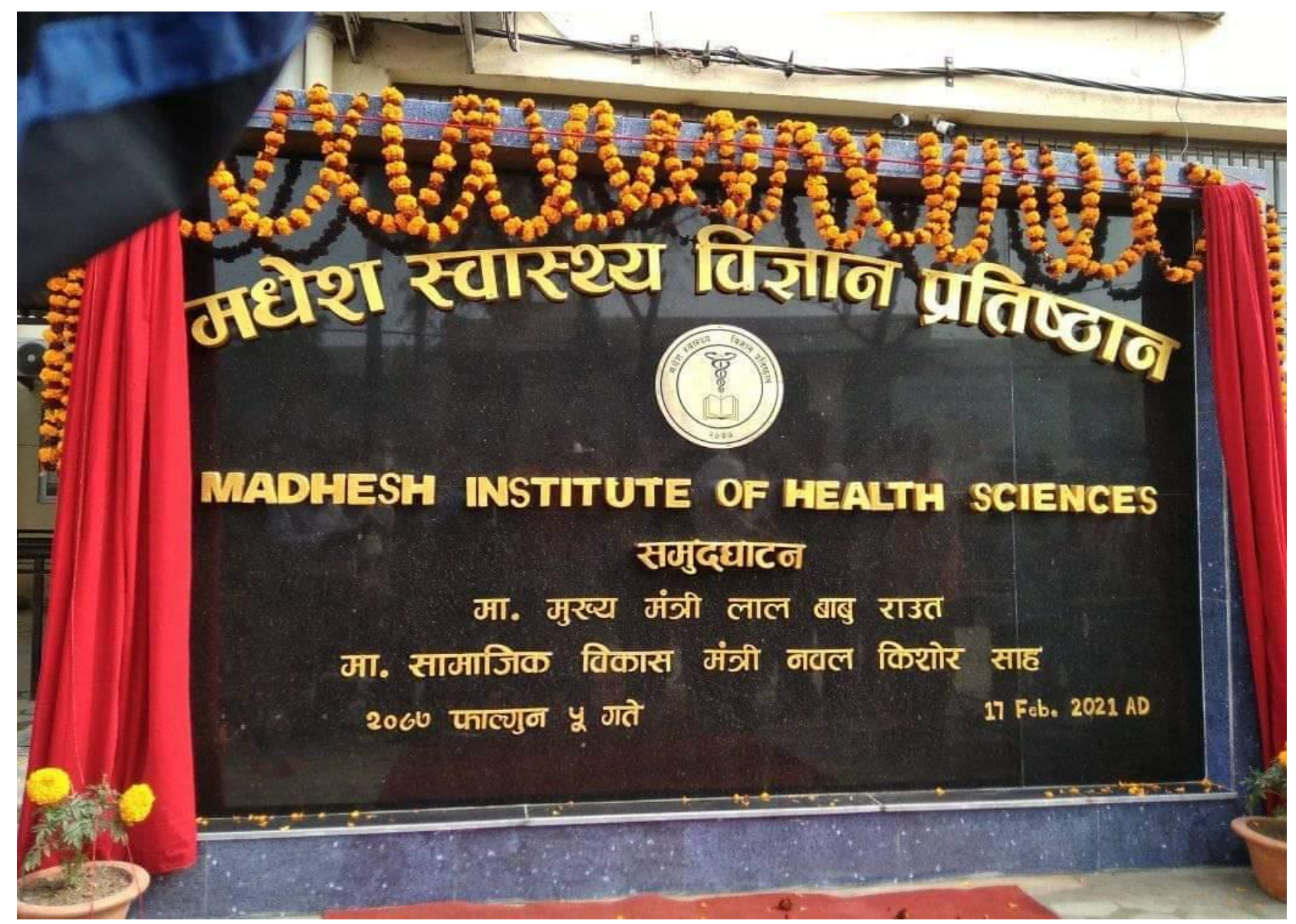

\section{Courtesy: MIHS [4]}

The inauguration of MIHS has been celebrated with rays of hope and great joy at Provincial hospital, Janakpurdham. But, the speed of action plan seems to be far yet, as its senate has not been convened till now. Approval of academic program is a vital concern to run the session on due time. The approval of budgets is another foremost issue that has to be granted almost immediately. Without financial support, it's very critical to speed up the pace of budding MIHS with its framework in Province 2.

The health structure and human resource management have continually been an additional challenge and are not sufficient to provide adequate health service delivery within the context of changing burden of disease, the growing advancement in health care technologies and also the increasing population in Province 2. Either to cope with the desired human resources in Provincial hospitals, nepotism has grabbed inveterately from its history through recruiting required human resources on a temporary basis, as a volunteer and on contract basis; Provincial hospital of Janakpurdham is also not untouched from this. However, MIHS can produce vacancies and recruit health professionals without political influence, free from discrimination and disparities is additionally a key concern. A healthy and competitive atmosphere is sort of essential for the prospering journey of MIHS in quality health care service.

The health human resources at MIHS should be technically competent, socially responsible and willing, and be able to meet the prevailing and rising health care challenges in province 2 . Moreover, MIHS additionally needs to attract, encourage and nurture young energetic talents of this province to become leaders in their fields of health-related sciences and thereby shape the future system of medical education, medical research and health care services system in province 2. Currently, the official setup of MIHS is at provincial hospital of Janakpurdham, that isn't suitably satisfactory to meet the goal of running academic programs of 
medical, nursing, and associated paramedics with the limited infrastructure of the provincial hospital. The provincial government has not yet endorsed any visionary preparation towards infrastructure and academic sessions.

Easy health care access and quality of treatment are a burning issue in this province. Despite the challenges, MIHS presents with opportunity and hope for health sector reform in province 2. Also, province 2 has been facing a gap between the level of medical treatment and care that is available in advanced medical centers at Kathmandu, major urban health centres in Nepal and in the developed world. To narrow these gaps, MIHS would serve as a hale and hearty bridge to provide better health service for province 2 and also the entire nation. Being a dream project, the formation of MIHS is an ambitious innovative historical decision under federalism but a progressive move of the government and authorities are expected to encompass greater results. Extensive capacity building on evidence-based planning, monitoring,

\section{REFERENCES}

1. Rubio DJ. The impact of decentralization of health ervices on health outcomes: evidence from Canada. Appl Econ. 2011; 43(26): 3907- 3917.

2. Ministry of Health and Population. Progress for the health sector. Report for the joint annual review, 2018. 3. evaluation, effective budgeting, strengthening leadership, logistics, human resources, and overall management of the health service delivery is important to strengthen MIHS and to improve health system reform, equitable access, improved quality of services, and multi-sectoral approaches in province 2 .

Necessity is the mother of invention, and I am hopeful with all my good wishes and smart desires towards MIHS to be designed as a medical hub within the field of medicine and health system of Nepal. Carefully, I draw eye of the government and better authorities of this establishment to create MIHS as a robust pillar within the health sector to address medical challenges faced in province 2 and gain quality for its superior health care facility to deliver preventive, promotive, and curative health services at this province and also to the nation. Further, I believe MIHS will be considered as the pride of Madhesh and its contribution can gleam ever and forever within the medical history of Nepal.
3. Gautam M. Available at: https://kathmandupost.com/miscellaneous/201 7/11/14/province-2-fares-poorly-in-healthindicators .Published at: November 14, 2017. Accessed on: 27 $7^{\text {th }}$ Feb 2021.

4. Madhesh Institute of Health sciences, Website: https://www.mihs.edu.np/. 2021

\section{ARTICLE INFO}

\section{Article History}

Received: 9 March, 2021

Revised: 26 March, 2021

Accepted: 19 May, 2021

\section{*Correspondence:}

Mrs. Khushbu Yadav

Department of Health Science,

Mithila Technical Academy, Janakpurdham, Nepal.

E-mail: meetkhushi20@gmail.com

ORCID: 0000-0001-5001-3983

\section{Citation:}

Yadav K. Madhesh Institute of Health

Sciences (MIHS): A Dream Project of

Medical Science in Province 2, Nepal.

MedS. J. Med. Sci. 2021;1(1):128-130 